BMJ Nutrition,

Prevention \& Health

\section{Breastfeeding exposure is associated with better knowledge of and attitudes toward BF in Kuwaiti women}

${ }^{1}$ Food Science and Nutrition, Kuwait University, Aladailiya, Kuwait

${ }^{2}$ Nutrition and Food Science, University of Maryland, College Park, Maryland, USA

Correspondence to Dr Dalal Usamah Alkazemi, Food Science and Nutrition, Kuwait University, Aladailiya, Kuwait; dalal.alkazemi@ku.edu.kw

Received 6 February 2019 Revised 27 September 2019 Accepted 4 October 2019 Published Online First 2 November 2019
Check for updates

(C) Author(s) (or their employer(s)) 2019. Re-use permitted under CC BY-NC. No commercial re-use. See rights and permissions. Published by BMJ.

To cite: Alkazemi DU, Jackson R. bmjnph 2019;2:100-109.

\section{ABSTRACT}

Objectives Breastfeeding (BF) has many benefits for both infants and mothers. However, despite evidence in support of BF, its prevalence has remained low in Kuwait. The purpose of this study was to (1) assess and describe BF attitudes and knowledge among women at a college campus; (2) evaluate BF exposures and sociodemographic factors associated with attitudes toward BF; (3) determine the association between BF knowledge and attitudes. Materials and methods This survey was a cross-sectional descriptive study conducted from February to April 2016. A convenience sample of 330 women (students, faculty and staff) from the College of Life Sciences (CLS) at Kuwait University participated in the survey.

Results Most of the participants respected women who breast fed (81.8\%). Some participants believed that BF a baby is painful (43.3\%), makes the breasts sag (35.8\%), and restricts the mothers' freedom (51.5\%). Additionally, $47.6 \%$ of the participants reported that they would feel embarrassed if they saw a woman BF her baby. Acceptability of BF in public was low and most participants preferred BF only around friends and family (52.4\%). A statistically significant positive association was observed between $B F$ knowledge and attitudes $\left(R^{2}=6.5 \%, p<0.001\right)$; however, the relationship was not independent and was also associated with nationality and having been breast fed as a baby $\left(R^{2}=10.3 \%, p=0.021\right)$.

Conclusion BF knowledge is important to encourage positive BF attitudes, and both are enforced with family values and practice across generations.

\section{INTRODUCTION}

Increasing breastfeeding (BF) rates is a global public health priority. ${ }^{2}$ The health benefits of $\mathrm{BF}$ for both mother and infant are well established. ${ }^{3}$ The WHO and UNICEF recommend that infants should be exclusively breast fed for the first 6 months of life, with continued BF and complementary feeding up to 24 months or longer. ${ }^{4}$ Exclusive BF for 6 months has been shown to improve infant health and development and lower morbidity from gastrointestinal and allergic diseases. BF also decreases the risk of a variety of chronic diseases and many other illnesses later in life for the mother, such as breast cancer and ovarian cancer; and type II diabetes for both the mother and her baby. ${ }^{56}$

Despite these demonstrated BF benefits, the prevalence and duration of $\mathrm{BF}$ in many countries remain lower than the recommendations. Social, economic and cultural lifestyle changes in the Gulf Cooperation Council (GCG) countries have been implicated in the decline of the prevalence and duration of BF. In the GCC member states, including the United Arab Emirates, Bahrain, Saudi Arabia, Oman, Qatar and Kuwait, the rate of exclusive BF for 6 months is below $35 \%$. To counter this, in Kuwait, all government hospitals are joining a Baby-Friendly Hospital Initiative (BFHI). ${ }^{7}$ Over $85 \%$ of Kuwaiti mothers breast feed their babies initially. However, the prevalence of exclusive BF up to the age of 6 months is only $19.5 \%{ }^{7}$ Dashti et al reported that at discharge from the hospital, about $84.8 \%$ of women reported BF their infants, with $10.5 \%$ exclusively BF. A later study found that $2 \%$ of infants had been predominantly breast fed for 26 weeks. ${ }^{8}$ Other investigators reported that $26.5 \%$ of women had breast fed their youngest infant for 6 months or more; however, in addition to exclusive $\mathrm{BF}$, this study included BF combined with other foods, liquids, or formula. ${ }^{9}$

Globally, a wide range of sociocultural and physiological factors significantly influence the variability in $\mathrm{BF}$ practices, including socioeconomic status, education, ethnicity, modernization, urbanisation, cultural beliefs and local feeding practices that affect a woman's decision and ability to breast feed successfully. $^{10}$ Infant feeding decisions depend heavily on maternal attitudes and perceptions toward BF, which may be formed as early as adolescence. ${ }^{11}$ Researchers have found that BF knowledge and prior exposure are predictors of BF intention. ${ }^{12}$ Other factors that affect the duration of $\mathrm{BF}$ include gender roles, attitudes of friends and relatives toward $\mathrm{BF}$, and social support. ${ }^{13}$ Early introduction of 
formula feeding is associated with embarrassment, insufficient maternity leave, lack of social support, and concerns about infant weight gain or breast milk quality. ${ }^{14}$

Our study provides a valuable culture-specific insight into the determinants of $\mathrm{BF}$ intentions and infant feeding choices. There have been several efforts to investigate these factors among young mothers and college students around the globe, including Kuwait, ${ }^{15}$ Yemen, ${ }^{16}$ Saudi Arabia, ${ }^{17-19}$ Jordan, ${ }^{20}$ Lebanon and Syria,${ }^{21}$ the USA, ${ }^{13}$ Hong Kong ${ }^{22}$ and China. ${ }^{23}$ To the best of the authors' knowledge, ours is the first study to assess the relationship between BF knowledge and attitudes using validated scales in a sample of Kuwaiti college students, faculty and staff. The aims of the study were to (1) assess and describe BF attitudes and knowledge among female students, faculty and staff at Kuwait University (KU); (2) evaluate factors associated with attitudes toward $\mathrm{BF}$ and knowledge such as BF exposures, sociodemographic factors, and body weight; (3) identify the association between $\mathrm{BF}$ knowledge and attitudes.

\section{MATERIALS AND METHODS Design and population}

We conducted a cross-sectional exploratory survey among female students, faculty members and staff at the College of Life Sciences (CLS) in KU. CLS is a small and relatively new college; it was established in 2003 under the name 'College for Women'. CLS consists of the following three departments: Environmental Technology Management, Food Science and Nutrition (FSN) and Communication Disorders Science. Most students are females, with only a few male students on campus. Data collection took place between February and April 2016. Research assistants recruited participants through a simple introduction to the study objectives and distributed the questionnaire to any students, faculty, or staff members present on campus who were willing to participate. Faculty and staff were invited to participate by visiting them in their office and work place; whereas students were invited to voluntarily participate in the study during breaks between classes. Two female investigators responsible for the data collection also explained the study's objectives, procedures, and the content of the data collection tool to participants. The questionnaire took less than $15 \mathrm{~min}$ to complete, and the return rate was $82.5 \%$ (330 of 400).

\section{Survey questionnaire}

A survey tool was designed to assess BF exposure; knowledge and attitudes scales were adopted from previous studies including Tarrant $e t a l^{23}$ Giles $e t a l^{13}$ and Lou et $a l^{24}$ The questions were extracted from various survey tools including the Iowa Infant Feeding Attitude Scale,$^{25}$ of which an Arabic version was recently validated among Lebanese women. ${ }^{26}$ However, it was important to develop a culturally appropriate local questionnaire for Kuwaiti women, as there are prominent cultural differences between Kuwait and Lebanon. For local validation, survey questions were reviewed for face validity by two faculty members in Nutrition and were translated to Arabic and back translated to English by two different professional translators. Student researchers also reviewed the Arabic version to ensure that the wording was culturally appropriate to Kuwait. Inconsistencies between the two versions were discussed and revised by faculty members. The final questionnaire was piloted among 50 undergraduate students and five women (non-students), and accordingly, the content was further revised. Culturally sensitive questions, such as the intent to breast feed for unmarried women, were reformatted to be directed only to those who were married, and questions on alcohol intake during lactation were removed. The final version consisted of 46 items. The questionnaire was made available in both the Arabic and English languages for the participants' convenience. The questionnaire items were coded uniformly in English for consistent data entry. The research team directly entered all data in English into an SPSS (V.24) spreadsheet.

Demographic data included current age, KU position (student, faculty, or staff), the major area of specialisation (for students), income per year, nationality (Kuwaiti vs non-Kuwaiti) and marital status. Prior BF exposure items included 'are you BF, or have you ever breast fed', 'were you breast fed when you were a baby?', 'do you know someone who has breast fed a baby?' and 'have you ever witnessed a woman breast feed her baby?' Possible responses included 'yes', 'no' and 'unsure'. To explore family involvement in decision-making to breast feed, the participants were asked to respond to the following statement: 'The decision to breast feed should be made'; with the following options included 'entirely by the mother', 'mostly by the mother', 'by the entire family', or 'by others'.

The BF knowledge scale consisted of 12 statements relating to $\mathrm{BF}$ behavioural awareness and benefits. Participants answered, 'agree', 'unsure', or 'disagree', which for scaling was coded as 1 for the correct response and 0 for the other responses. The total $\mathrm{BF}$ knowledge score ranged from 0 to 12 , with higher scores indicating greater BF knowledge. The $B F$ attitudes scale consisted of 15 statements that convey feelings and thoughts toward $\mathrm{BF}$, with responses constructed on a 5-point Likert scale from 1-'strongly disagree' to 5 -'strongly agree'. The total score ranged from 15 to 75 , with higher scores representing a more positive attitude toward BF. The attitudes scale was further divided into two scales: $\mathrm{BF}$ advantages and concerns, according to Lou et $a l^{22}$ The BF advantages subscale included six statements, with scores ranging from 6 to 30; whereas the concerns subscale included nine statements with scores ranging from 9 to 45. After piloting the survey tool, the Cronbach's alpha of 0.83 was determined for the total $\mathrm{BF}$ attitudes scale, and 0.71 for the BF knowledge scale, demonstrating acceptable reliability for both.

\section{Statistical analysis}

Descriptive statistics were used to analyse participants' characteristics. Categorical variables were compared with Pearson's $\chi^{2}$. Fisher's exact tests were used whenever $20 \%$ of the 
Table 1 Population sociodemographic characteristics $(n=330)$

\begin{tabular}{|c|c|c|c|}
\hline $\begin{array}{l}\text { Population } \\
\text { characteristics }\end{array}$ & $\begin{array}{l}\text { Total, n (\%) } \\
330(100)\end{array}$ & $\begin{array}{l}\text { Students, } \\
\text { n (\%) } 224 \\
(67.9)\end{array}$ & $\begin{array}{l}\text { Faculty and } \\
\text { staff, n (\%) } \\
106(32.1)\end{array}$ \\
\hline \multicolumn{4}{|l|}{ Age (years) } \\
\hline Under 21 & 123 (37.3) & $121(54.1)^{\star}$ & $2(1.9)^{\star} \dagger$ \\
\hline $21-30$ & 143 (43.3) & $102(45.5)^{*}$ & $41(38.7)^{\star} \dagger$ \\
\hline$>30$ & 64 (19.4) & $1(0.4)^{*}$ & $63(59.4)^{*} \dagger$ \\
\hline \multicolumn{4}{|l|}{ Weight status } \\
\hline $\begin{array}{l}\text { Non-overweight, } \\
\mathrm{BMl}<25\end{array}$ & 167 (50.6) & $124(55.4)^{\star}$ & $43(40.6)^{\star} \dagger$ \\
\hline $\begin{array}{l}\text { Overweight or } \\
\text { obese, } \mathrm{BMI} \geq 25\end{array}$ & 163 (49.4) & $100(44.6)^{*}$ & $63(59.4)^{*} \dagger$ \\
\hline
\end{tabular}

Monthly family

income

\begin{tabular}{lrrr|}
\hline 2500, KD & $219(72.4)$ & $163(72.8)^{\star}$ & $56(52.8)^{*} \dagger$ \\
\hline 2500, KD & $91(27.6)$ & $61(27.2)^{\star}$ & $50(47.2)^{*} \dagger$ \\
Nationality & & & \\
Kuwaiti & $271(82.1)$ & $196(87.5)^{\star}$ & $75(70.8)^{\star} \dagger$ \\
Non-Kuwaiti & $59(17.9)$ & $28(12.5)^{\star}$ & $31(29.2)^{*} \dagger$
\end{tabular}

\section{Education}

$\begin{array}{lccc}\begin{array}{l}\text { Less than a } \\ \text { college bachelor }\end{array} & 239(72.4) & 217(96.9)^{\star} & 22(20.8)^{\star} \dagger \\ \begin{array}{l}\text { College bachelor } \\ \text { or higher }\end{array} & 91(27.6) & 7(7.7)^{\star} & 84(79.2)^{\star} \dagger \\ & & & \end{array}$

\begin{tabular}{lrrr} 
Marital status & & & \\
Single & $249(75.5)$ & $51(22.8)$ & $30(28.3)$ \\
Married & $81(24.5)$ & $173(77.2)$ & $76(71.7)$ \\
\hline
\end{tabular}

*Different superscript letters note statistical significance with $\chi^{2}$ statistics.

$\mathrm{tp}<0.001$.

BMI, body mass index.

expected cell frequencies were $\leq 5$. Parametric variables were analysed using Student's t-tests and analysis of variance. All reported $p$ values were two-sided tests and were considered statistically significant at $\mathrm{p}<0.05$. To identify factors associated with $\mathrm{BF}$ attitudes and knowledge, stepwise multivariate regression analysis was performed with the total scores for each scale transformed into standardised Z-scores to allow for parametric tests. Analyses were performed using IBM SPSS Statistics for Windows, V.24.

\section{RESULTS}

\section{Participants' characteristics}

The characteristics of the total sample $(n=330)$ are shown in table 1 . The age difference between the student and faculty/staff groups was statistically significant. In addition, compared with the faculty/staff group, students had lower income, lower educational level, a lower percentage of overweight or obese individuals, and a higher percentage of Kuwaiti nationals. The non-Kuwaiti in the total sample were from Saudi Arabia $(n=12)$, Bahrain $(n=3)$, Oman $(n=2)$, Syria $(n=5)$, Lebanon $(n=8)$, Iraq $(n=2)$, India $(n=5)$, Pakistan $(n=3)$, Canada $(n=4)$ and USA $(n=3)$. Two participants did not report their nationality.

\section{BF exposure and the mean scores of knowledge of and attitudes toward BF}

$\mathrm{BF}$ exposure measures are shown in table 2. Most of the women surveyed reported a high level of BF exposure. The mean knowledge score for all participants was high at $82.8 \%$ of 12 possible points (table 3 ). The mean attitudes score was low in our total sample at $65.7 \%$ of 73 possible points (table 3 ).

\section{Factors associated with knowledge of and attitudes toward BF}

Lower positive attitudes toward BF were observed among Kuwaiti women than among non-Kuwaiti women (48.6 \pm 8.9 vs $52.6 \pm 9.7, \mathrm{p}=0.002$ ), with Kuwaitis scoring lower on both the advantages score $(23.5 \pm 4.5$ vs $24.9 \pm 3.9, \mathrm{p}=0.026)$ and the concerns score $(25.1 \pm 7.5$ vs $27.6 \pm 8.6, \mathrm{p}=0.02)$. None of the other sociodemographic variables tested (income, education and marital status) were significantly different between the groups. Further, the knowledge scores did not vary according to $\mathrm{BF}$ exposure variables except for the following two exposures: if the woman was breast fed as a child and if she knew someone who had breast fed a baby. Women who answered yes to these two statements scored higher on knowledge than those who answered 'no' and 'unsure' $(10.11 \pm 1.50$ vs $9.43 \pm 1.87, \mathrm{p}=0.007$ and $10.04 \pm 1.56$ vs $8.82 \pm 2.2, \mathrm{p}=0.002$, respectively). Similarly, the mean attitude scores differed only between women who were breast fed as a baby. Those who reported 'yes' had higher positive attitude scores toward BF than those who reported 'no' or 'unsure' ( $50.73 \pm 9.75$ vs $45.68 \pm 9.5, \mathrm{p}=0.002)$, scoring higher on both the advantages and the concerns scales.

\section{Misinformation associated with BF}

Common misinformation regarding BF knowledge was identified among our participants (table 4). More than $30 \%$ of participants thought that the nutritional value of breast milk and infant formula are the same; $29 \%$ of participants disagreed or were unsure that most women can make enough breast milk to feed their baby adequately; and $25 \%$ agreed that women who have small breasts cannot make enough breast milk.

\section{Attitudes toward BF}

Participants were split on whether BF is more convenient than formula feeding, with $50 \%$ agreeing, $26.4 \%$ disagreeing and $23.6 \%$ unsure (table 5). Most participants respected women who breast feed (80.6\%), and more faculty and staff agreed that they respected women who breast feed than students $(88.7 \%$ vs $76.8 \%$, $\mathrm{p}=0.038$ ). However, more than half of the women agreed that formula feeding gives more freedom to the mother; and $61 \%$ agreed that mothers should wean their babies before they return to work or school. Almost a 
Table 2 The proportion of participants reported as $n(\%)$ for the breastfeeding (BF) exposures for the total population $(n=330)$, and per students $(n=224)$, faculty and staff $(n=106)$

\begin{tabular}{|c|c|c|c|}
\hline BF exposure & $\begin{array}{l}\text { Total n (\%) } \\
330(100)\end{array}$ & $\begin{array}{l}\text { Students n (\%) } \\
224(67.9)\end{array}$ & $\begin{array}{l}\text { Faculty and staff } n(\%) \\
106(32.1)\end{array}$ \\
\hline \multicolumn{4}{|l|}{ Have children } \\
\hline Yes & 60 (18.2) & $22(9.8)^{*}$ & $38(35.8)^{\star} \dagger$ \\
\hline No & $270(81.8)$ & $202(90.2)^{*}$ & $68(64.2)^{*} \dagger$ \\
\hline \multicolumn{4}{|l|}{ Pregnant currently } \\
\hline Yes & $19(5.8)$ & $13(5.8)$ & $6(5.7)$ \\
\hline No & 310 (94.2) & $210(94.2)$ & $100(94.3)$ \\
\hline \multicolumn{4}{|l|}{ BF currently } \\
\hline Yes & $17(5.2)$ & $10(4.5)$ & $7(6.6)$ \\
\hline No & $312(94.8)$ & $213(95.5)$ & 99 (94.8) \\
\hline \multicolumn{4}{|l|}{ Ever breast fed } \\
\hline Yes & $47(14.2)$ & $18(8)^{*}$ & $29(27.4)^{\star} \dagger$ \\
\hline No & $283(85.8)$ & $206(92)^{*}$ & $77(72.6)^{*} \dagger$ \\
\hline \multicolumn{4}{|l|}{ Breast fed when baby } \\
\hline Yes & $228(69.1)$ & $156(69.6)$ & 72 (67.9) \\
\hline No & $37(11.2)$ & $22(9.8)$ & 15 (14.2) \\
\hline Unsure & 65 (19.7) & $46(20.5)$ & $19(17.9)$ \\
\hline \multicolumn{4}{|c|}{ Know someone who has breast fed } \\
\hline Yes & $294(89.1)$ & $199(88.8)$ & $95(89.6)$ \\
\hline No & $22(6.7)$ & $16(7.1)$ & $6(5.7)$ \\
\hline Unsure & $14(4.2)$ & $9(4)$ & $5(4.7)$ \\
\hline \multicolumn{4}{|c|}{ Ever witnessed a woman BF } \\
\hline Yes & $297(90)$ & 201 (89.7) & $96(90.6)$ \\
\hline No & $28(8.5)$ & $19(8.5)$ & $9(8.5)$ \\
\hline Unsure & $5(1.5)$ & $4(1.8)$ & $1(0.9)$ \\
\hline \multicolumn{4}{|c|}{ Support friends or relative members to breast feed } \\
\hline Yes & $307(93)$ & $210(93.8)$ & $97(91.5)$ \\
\hline No & $11(3.3)$ & $5(2.2)$ & $6(5.7)$ \\
\hline Unsure & $12(3.6)$ & $9(4)$ & $3(2.8)$ \\
\hline \multicolumn{4}{|c|}{ Decision to breast feed should be made by } \\
\hline Entirely by the mother & $238(72.1)$ & $163(72.8)$ & $75(70.8)$ \\
\hline Mostly by the mother & $37(11.2)$ & $24(10.7)$ & $13(12.3)$ \\
\hline By the entire family & $37(11.2)$ & $27(10.7)$ & $13(12.3)$ \\
\hline By others & $18(5.5)$ & $13(5.8)$ & $5(4.7)$ \\
\hline
\end{tabular}

*Different superscript letters note statistical significance with $\chi^{2}$ statistics. $\mathrm{tp}<0.001$.

third $(32.1 \%)$ of participants believed that BF prevents a woman from returning to her prepregnancy weight. A high proportion of participants were concerned that $\mathrm{BF}$ is painful and that it can make the breasts sag. More staff and faculty expressed concerns toward experiencing pain with BF than students; furthermore, more staff and faculty thought formula feeding gives more freedom to the mother (table 6). More than a third of participants reported feeling uncomfortable seeing other women on TV or in a magazine breast feed. More than half of the participants agreed that BF should be done only around friends and family, and $47.6 \%$ of participants agreed that they would feel embarrassed if they saw a woman $\mathrm{BF}$ a baby. These attitudes towards BF did not differ when comparing women with and without children, and women who were married or single (data not shown).

\section{Final correlates of attitudes toward BF}

Stepwise multivariable regression analysis (table 7) revealed that $\mathrm{BF}$ knowledge and being non-Kuwaiti were both positively associated with $\mathrm{BF}$ attitudes $(\mathrm{B}=0.225$, $\mathrm{p}<0.0001$ and $\mathrm{B}=0.147, \mathrm{p}=0.005$ ) whereas 'not being breast fed as a baby' is negatively associated with $\mathrm{BF}$ attitudes $(\mathrm{B}=-0.124, \mathrm{p}=0.021)$. This suggests that $\mathrm{BF}$ knowledge, 
Table 3 Student's t-test comparisons of total scores for breastfeeding (BF) knowledge, attitudes, advantages and concerns between Kuwait University (KU) positions categories, and by Kuwaiti versus non-Kuwaiti nationality

\begin{tabular}{|c|c|c|c|c|}
\hline Scores & $\begin{array}{l}\text { Total } \\
\mathrm{n}=330\end{array}$ & $\begin{array}{l}\text { Students versus } \\
\text { faculty and staff } \\
\text { ( } n=224 \text { vs 106) }\end{array}$ & $\begin{array}{l}\text { Kuwaiti versus non-Kuwaiti } \\
\text { ( } n=271 \text { vs } 59 \text { ) }\end{array}$ & P value* \\
\hline \multirow[t]{2}{*}{ BF knowledge } & $9.9 \pm 1.6$ & $9.8 \pm 1.7$ & $9.9 \pm 1.7$ & \\
\hline & & $10.2 \pm 1.5$ & $10.1 \pm 1.3$ & \\
\hline$\%$ BF knowledge & $82.8 \pm 13.7$ & $81.8 \pm 14.1$ & $82.4 \pm 14.2$ & \\
\hline BF attitude & & $49.6 \pm 9.7$ & $52.6 \pm 9.7 \dagger \ddagger$ & \\
\hline \multirow[t]{2}{*}{$\%$ Total BF attitudes } & $65.7 \pm 12.2$ & $65.5 \pm 11.9$ & $64.8 \pm 11.9 \dagger$ & 0.002 \\
\hline & & $66.2 \pm 12.9$ & 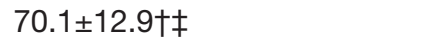 & \\
\hline BF advantages & $23.8 \pm 4.4$ & $23.5 \pm 4.3$ & $23.5 \pm 4.5 \dagger$ & 0.026 \\
\hline \multirow[t]{2}{*}{ BF concerns } & $25.5 \pm 7.8$ & $25.6 \pm 7.6$ & $25.1 \pm 7.5 a$ & 0.02 \\
\hline & & $25.6 \pm 7.6$ & 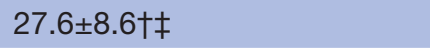 & \\
\hline \multirow[t]{2}{*}{$\%$ BF concerns } & $56.7 \pm 17.3$ & $56.8 \pm 16.8$ & $55.6 \pm 16.7 \dagger$ & 0.02 \\
\hline & & $56.5 \pm 18.3$ & 61.4ะ19.1†キ & \\
\hline
\end{tabular}

${ }^{*} \mathrm{P}$ value significant at $<0.05$.

†Different superscript letters note statistical significance with Student's t-test statistics. $\neq \mathrm{p}<0.01$.

non-Kuwaiti nationality, and being breast fed as a baby are associated with more positive BF attitudes. All other tested sociodemographic variables were not significant, including $\mathrm{KU}$ position, marital status and age.

\section{DISCUSSION}

Mothers' infant nursing decisions are largely dependent on their knowledge of and attitude toward BF. This study showed that our sample of women had sound BF knowledge, experience and exposure. Most participants were well informed about infants' health benefits from BF, knowing that it decreases the risk of illness and prevents respiratory infections, and most also knew that $\mathrm{BF}$ can protect mothers from breast cancer. ${ }^{27}$ More than half of the student participants were majoring in FSN and were frequently exposed to health campaigns. In addition, the FSN department often organises health promotional activities for their students. Such activities can increase the college community's knowledge on health issues such as $\mathrm{BF}$ and may explain why there were no differences noted in knowledge or attitudes among CLS students, faculty and staff. This may also explain why there were no differences noted in BF knowledge according to students' major area of specialisation, which was found by other studies. ${ }^{21}{ }^{22}$ Similarly, the major area of specialisation was not related to BF attitudes. Nutrition students are expected to be more knowledgeable about the biology of lactation, the nutrient requirements of women and infants, and the policy issues related to BF initiation and duration, and so on, than non-nutrition students or educated faculty. Among our participants, however, BF knowledge and attitudes were more likely modulated by experiences and exposure to other women who breast fed or by whether the woman herself was breast fed as a baby. The personal experience of being breast fed as a child likely reflects the home environment and the attitude toward BF held by female family members. Additionally, the tradition of women marrying at a young age in the GCC exposes women to the BF experience and precipitates knowledge and attitudes before any formal education on $\mathrm{BF}$ is received at the college level. Alongside government efforts regarding BFHI, maternity hospitals should provide mothers with $\mathrm{BF}$ education and support throughout pregnancy and after delivery. We did not investigate this aspect in our survey; therefore, it is of interest for future studies to distinguish the most effective methods of BF education in Kuwait.

Women who were married or expecting had high positive attitudes toward $\mathrm{BF}$-more than half intended to breastfeed their babies and more than a third intended to breast feed exclusively for 6 months. Our participants expressed the intention to support a friend or relative to breast feed, and the majority agreed that the decision to breast feed should be made entirely by the mother. Many studies reported that women value their grandmothers for providing practical support and as major influences 
Table 4 Breastfeeding (BF) knowledge examined among participants and their answers categorised per group

\begin{tabular}{|c|c|c|c|c|}
\hline BF knowledge & & $\begin{array}{l}\text { Total N (\%) } \\
330(100)\end{array}$ & $\begin{array}{l}\text { Students N (\%) } \\
224(67.9)\end{array}$ & $\begin{array}{l}\text { Faculty and } \\
\text { staff } N(\%) \\
106(32.1)\end{array}$ \\
\hline \multirow{2}{*}{$\begin{array}{l}\text { 1. BF should be started within the first hour } \\
\text { after birth }\end{array}$} & Agree & $263(79.7)$ & 179 (79.9) & 84 (79.2) \\
\hline & Disagree or unsure & 67 (20.3) & $54(20.1)$ & $19(29.7)$ \\
\hline \multirow{2}{*}{$\begin{array}{l}\text { 2. The first food for babies should be breast } \\
\text { milk }\end{array}$} & Agree & $313(94.8)$ & 212 (94.6) & $101(95.3)$ \\
\hline & Disagree or unsure & $17(5.2)$ & $12(5.4)$ & $5(4.7)$ \\
\hline \multirow{2}{*}{$\begin{array}{l}\text { 3. BF alone provides sufficient nutrition in the } \\
\text { first } 6 \text { months of life for the baby }\end{array}$} & Agree & $310(93.9)$ & $210(93.8)$ & $100(94.3)$ \\
\hline & Disagree or unsure & $20(6.1)$ & $14(6.3)$ & $6(5.7)$ \\
\hline \multirow{2}{*}{$\begin{array}{l}\text { 4. BF helps prevent respiratory infections in the } \\
\text { baby }\end{array}$} & Agree & $305(92.4)$ & 205 (91.5) & $100(94.3)$ \\
\hline & Disagree or unsure & $25(7.6)$ & $19(8.5)$ & $6(5.7)$ \\
\hline \multirow{2}{*}{$\begin{array}{l}\text { 5. Formula-fed babies may suffer from more } \\
\text { illness than breastfed babies }\end{array}$} & Agree & $279(84.5)$ & $190(84.8)$ & $89(84)$ \\
\hline & Disagree or unsure & $51(15.5)$ & 34 (15.2) & $17(16)$ \\
\hline \multirow{2}{*}{$\begin{array}{l}\text { 6. The benefits of BF for babies continue even } \\
\text { after weaning }\end{array}$} & Agree & $278(84.2)$ & $184(82.1)$ & $94(88.7)$ \\
\hline & Disagree or unsure & $52(15.8)$ & 40 (17.9) & $12(11.3)$ \\
\hline \multirow[t]{2}{*}{ 7. BF will help a mother feel closer to her baby } & Agree & $312(94.5)$ & $210(93.8)$ & $102(96.2)$ \\
\hline & Disagree or unsure & $18(5.5)$ & $14(6.3)$ & $4(3.8)$ \\
\hline \multirow{2}{*}{$\begin{array}{l}\text { 8. Women who have breast fed have a lowered } \\
\text { risk of breast cancer }\end{array}$} & Agree & $285(86.4)$ & $192(85.7)$ & $93(87.7)$ \\
\hline & Disagree or unsure & $45(13.6)$ & $32(14.3)$ & $13(12.3)$ \\
\hline \multirow{2}{*}{$\begin{array}{l}\text { 9. Most women can make enough breast milk } \\
\text { to adequately feed their baby }\end{array}$} & Agree & $234(70.9)$ & $153(68.3)$ & $81(76.4)$ \\
\hline & Disagree or unsure & $96(29.1)$ & $71(31.7)$ & $25(23.6)$ \\
\hline \multirow{2}{*}{$\begin{array}{l}\text { 10. The nutritional value of breast milk and } \\
\text { infant formula are the same }\end{array}$} & Agree & $229(69.4)$ & $152(67.9)$ & $77(72.6)$ \\
\hline & Disagree or unsure & $101(30.6)$ & $72(32.1)$ & $29(27.4)$ \\
\hline \multirow{2}{*}{$\begin{array}{l}\text { 11. BF prevents a woman from returning to her } \\
\text { prepregnancy weight }\end{array}$} & Agree & $160(32.1)$ & $74(33)$ & $74(69.8)$ \\
\hline & Disagree or unsure & $224(67.9)$ & 170(67) & $32(30.3)$ \\
\hline \multirow{2}{*}{$\begin{array}{l}\text { 12. Women who have small breasts cannot } \\
\text { make enough breast milk }\end{array}$} & Agree & $83(25.2)$ & $61(27.2)$ & $22(20.8)$ \\
\hline & Disagree or unsure & $247(74.8)$ & $163(72.8)$ & 84 (79.2) \\
\hline
\end{tabular}

Binary scale was created for data table, items $1-9$ the correct answer is 'agree $=1$ ', whereas items $10-12$ the correct answer is 'disagree $=1$ '; 'unsure' was provided to detect automatic answering, and graded as 0.

on infant feeding decisions. ${ }^{28}$ Families who value $\mathrm{BF}$ as the most appropriate and nurturing feeding method through generations demonstrate a high support level and value the mother's feeding decisions. Other studies reported that women identified their husbands as the most needed support person with regards to infant feeding decisions, and less often involved their mothers. ${ }^{29}{ }^{30}$ Social support either from family members or a woman's partner is shown to affect mothers' decisions to initiate BF. ${ }^{831}$

Although BF is encouraged by the Islamic faith and the Quran (Islamic holy book) specifically mentions that BF should continue for the first 2years of life, this belief is not practiced as a result of attitude changes that have developed with lifestyle modernization in Kuwait. Our results showed that women understood the emotional connection that occurs through $\mathrm{BF}$ and most participants also knew that $\mathrm{BF}$ benefits continue even after weaning. However, some knowledge gaps exist around early feeding practices. Many participants did not know that BF should be started within the first hour after birth, a major recommendation of WHO for successful $\mathrm{BF}^{32}$ In maternity hospitals in Kuwait, timely initiation of $\mathrm{BF}$ is reported to be low at only $13 \%$ despite the pronouncement of two Kuwaiti hospitals as Baby Friendly in 2014 and $2015 .{ }^{7}$ Dashti $e t a l^{8}$ showed that delaying BF 24 or more hours after birth contributed to a high incidence of prelacteal feeding in a group of recently delivered mothers. Cultural beliefs about BF practices, postbirth complications, hospital birth management policies, and maternity ward staff guidelines and training may lead to delayed $\mathrm{BF}$ initiation. ${ }^{33} 34$

In our sample, Kuwaiti women had lower positive attitudes toward BF than their non-Kuwaiti counterparts. Additionally, Kuwaiti women recognised fewer advantages of $\mathrm{BF}$ and had fewer concerns; however, there were no differences in BF knowledge and BF intention among expectant participants. Indeed, Kuwaiti nationality was negatively associated with positive $\mathrm{BF}$ attitudes in the multivariate regression model confirming these observations. Similar to earlier findings from Dashti $e t a l,{ }^{8}$ non-Kuwaiti mothers who were from other Arab countries were more likely than Kuwaiti women to initiate $\mathrm{BF}$ and to exclusively breast feed their infants. We cannot determine the reason for 
Table 5 Breastfeeding (BF) advantages for the total numbers of participants, students and staff

\begin{tabular}{|c|c|c|c|c|c|}
\hline BF advantages & & $\begin{array}{l}\text { Total n (\%) } \\
330(100)\end{array}$ & $\begin{array}{l}\text { Students n (\%) } \\
224(67.9)\end{array}$ & $\begin{array}{l}\text { Faculty and } \\
\text { staff } n(\%) \\
106(32.1)\end{array}$ & $P$ value \\
\hline \multirow[t]{3}{*}{ Breast milk is cheaper than formula milk } & Agree & $188(57)$ & $127(56.7)$ & $61(57.5)$ & \\
\hline & Neutral & $79(23.9)$ & $55(24.6)$ & $24(22.6)$ & \\
\hline & Disagree & $63(19.1)$ & $42(18.8)$ & $21(19.8)$ & \\
\hline \multirow{2}{*}{$\begin{array}{l}\text { Breastfed babies are smarter than formula } \\
\text { fed babies }\end{array}$} & Agree & $186(56.4)$ & $123(54.9)$ & $63(59.4)$ & \\
\hline & Disagree & $54(16.4)$ & $38(17)$ & $16(15.1)$ & \\
\hline \multirow{3}{*}{$\begin{array}{l}\text { Breastfed babies grow better than formula } \\
\text { fed babies }\end{array}$} & Agree & $235(71.2)$ & $155(69.2)$ & $80(75.5)$ & \\
\hline & Neutral & $60(18.2)$ & $42(18.8)$ & $18(17)$ & \\
\hline & Disagree & $35(10.6)$ & $27(12.1)$ & $8(7.5)$ & \\
\hline \multirow[t]{3}{*}{ I respect women who breast feed } & Agree & $266(80.6)$ & $172(76.8)^{\star}$ & $94(88.7)^{\star} \dagger$ & 0.038 \\
\hline & Neutral & $41(12.4)$ & $33(14.7)$ & $8(7.5)$ & \\
\hline & Disagree & $23(7)$ & $19(8.5)$ & $4(3.8)$ & \\
\hline \multirow[t]{3}{*}{$\mathrm{BF}$ is more convenient than formula feeding } & Agree & $156(50)$ & $114(50.9)$ & $51(48.1)$ & \\
\hline & Neutral & $78(23.6)$ & $54(24.1)$ & $24(22.6)$ & \\
\hline & Disagree & $87(26.4)$ & $56(25)$ & $31(29.2)$ & \\
\hline
\end{tabular}

${ }^{*}$ Different superscript letters note statistical significance with $\chi^{2}$ statistics. $\dagger p<0.05$.

this discrepancy, but our results suggest that non-Kuwaiti women had more respect for women who breast feed. At the same time, Kuwaiti participants expressed more concerns about BF impairing freedom and that nursing would be painful. More faculty and staff ( $29 \%$ non-Kuwaiti) than students (12.5\% non-Kuwaiti) feared that BF was painful and made the breasts sag $(p<0.001)$, even though a higher proportion of them had children and more prior $\mathrm{BF}$ experiences. These concerns may result from negative BF experiences and lack of BF support from husbands and employers. ${ }^{35}$ Interestingly, previous researchers found that misconceptions regarding the effects of $\mathrm{BF}$ on breast shape were deeply rooted in the culture among Arab youth from Lebanon and Syria and were identified as a main reason for early cessation of $\mathrm{BF}^{22} 36$

Further, preconceived beliefs that most women, especially those with small breasts, cannot make enough milk to adequately feed their baby, can discourage BF. Delaying $\mathrm{BF}$ initiation and self-doubt regarding one's capability to produce milk may lead to BF mismanagement and further complications, which in turn can lead to frustration and increased formula use. Additionally, a large proportion of our sample believed that the nutritional value of breast milk and infant formula are the same, and that formula feeding offers more freedom and convenience to the mother. These concerns may lead working mothers, who may be unaware that $\mathrm{BF}$ is nutritionally superior to formula, to believe that $\mathrm{BF}$ is not worth the effort it requires. A previous study of 641 Saudi mothers showed that employment status and maternal education were the most important determinants for $\mathrm{BF}$ intention and exclusivity. ${ }^{20}$ The deterrents to $\mathrm{BF}$ or continuing to breast feed are reflected in the high percentage $(61 \%)$ of our participants agreeing that women should wean their babies before returning to work, despite the success of their $\mathrm{BF}$ experiences and exposures.

These frustrations associated with $\mathrm{BF}$ and work-related concerns were found to be barriers to exclusive BF in many studies. For example, among 600 Saudi mothers surveyed in Abha, work-related problems were identified as the most common barrier against exclusive BF $(46.2 \%) .{ }^{18}$ Other BF barriers identified among Saudi mothers were insufficient breast milk (34.2\%), maternal health issues $(14.9 \%)$, and neonatal health problems (9.7\%). ${ }^{18}$ Nassar et $a l^{10}$ showed that having no possibility of $\mathrm{BF}$ at work was among the factors that led to early BF cessation among Kuwaiti women. Other factors include the absence of husband's encouragement, living separately from the rest of family, later initiation of $\mathrm{BF}$, higher maternal age, $\mathrm{BF}$ information given after rather than before birth, and maternal and infant sickness. ${ }^{10}$ Qualitative studies in the Kuwaiti population subgroups are needed to evaluate how these factors vary.

As is common nationwide, overweight and obesity were high among our sample (45\% students and $59 \%$ of faculty and staff). Studies have found that obese women are less likely to breast feed and that maternal obesity seems to be 
Table 6 Breastfeeding (BF) concerns, reported here for the total number of participants, students, faculty and staff

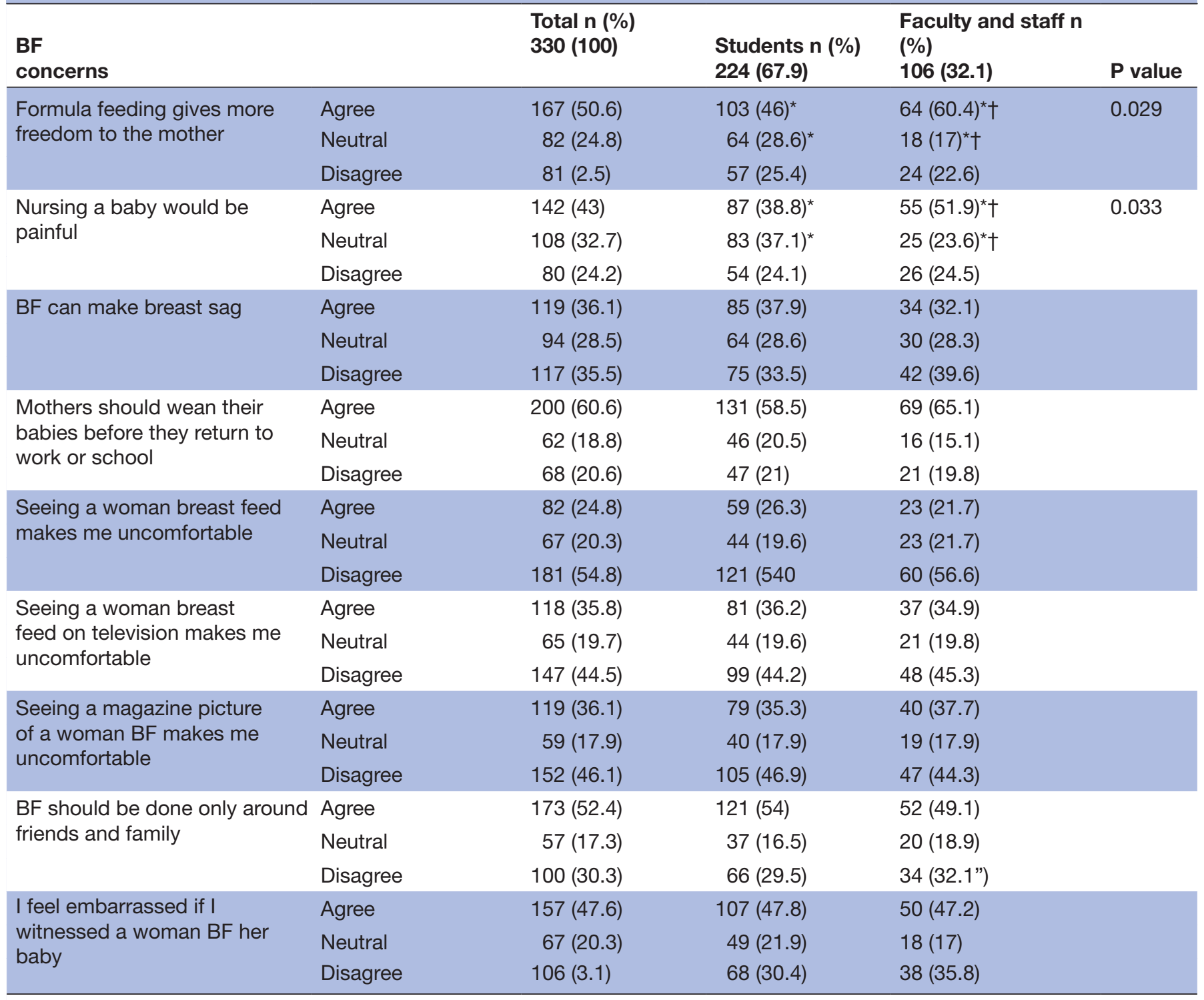

*Different superscript letters note statistical significance with $\chi^{2}$ statistics. $+\mathrm{p}<0.05$.

associated with a decreased initiation of $\mathrm{BF}$, a shortened duration of $\mathrm{BF}$, a less adequate milk supply, and delayed onset of lactogenesis II. ${ }^{37}$ However, we found no association between $\mathrm{BF}$ attitudes or intention according to weight status as was observed in a previous study. ${ }^{11}$ However, BF concerns, especially those associated with body image and weight, were present in our sample. Women with more experience of $\mathrm{BF}$ had more concern that $\mathrm{BF}$ prevents a woman from returning to her prepregnancy weight.

Our study supported other studies' findings that many women still associate BF with embarrassment. Most women reported that they would feel embarrassed if they saw women breast feed, and most preferred BF only around friends and family, which demonstrates the low acceptability of BF in public. Such self-imposed restrictions make BF inconvenient, especially for working women and students. Similarly, Ebrahim et $a l^{16}$ found low support for BF in public places among KU female students ( $\mathrm{n}=1106)$, and only $38 \%$ supported $\mathrm{BF}$ in female prayer rooms located in public places. There are ongoing local efforts among BF support groups to increase support for BF in public places by facilitating the use of rooms designated for women, such as the prayer rooms or a designated nursing room in baby-friendly shopping malls. For successful BF among working women, future interventions should address fears of freedom restriction and loss of independence associated with family issues, return to work, embarrassment and perceived social isolation.

This study also reinforces previous findings that BF knowledge is related to positive attitudes toward BF. However, our results show that the relationship is not independent, but also related to a woman's exposure to BF, including her own experiences with $\mathrm{BF}$ and her family environment. Family values regarding BF adopted by the individual and 
Table 7 Stepwise multivariable regression models for breastfeeding (BF) attitudes as the dependent variable, and BF knowledge, nationality and being breast fed as a baby as predictors

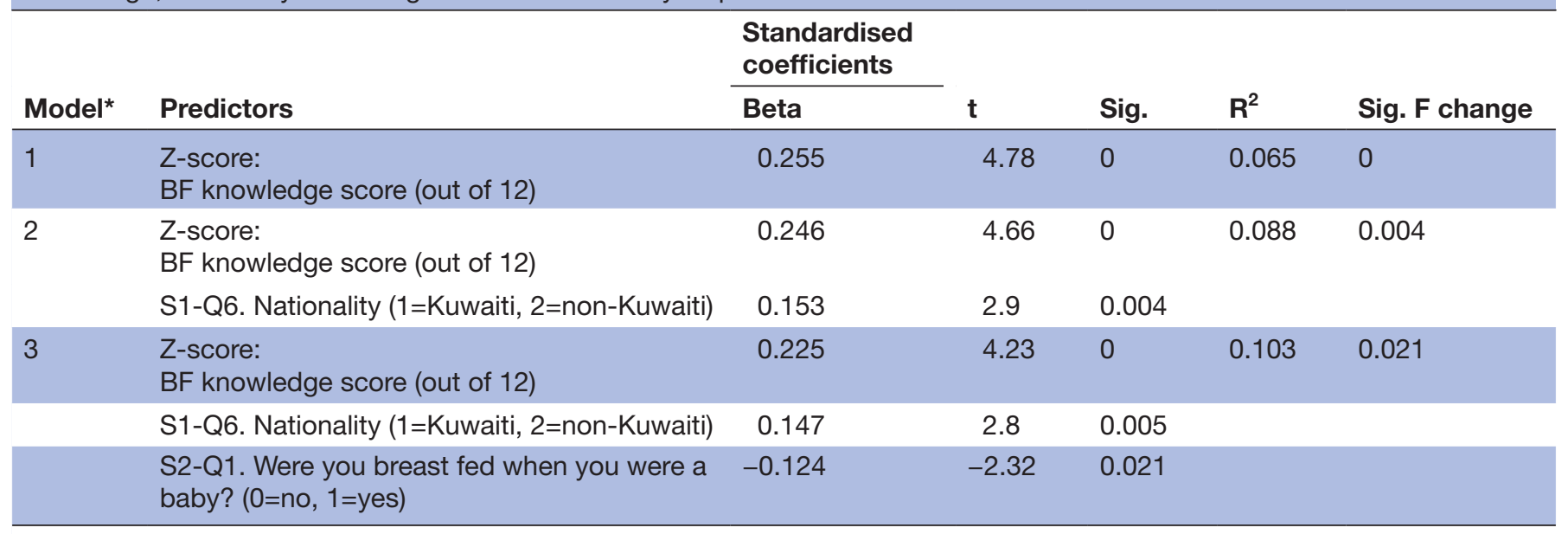

*Dependent variable: Z-score: total attitudes score out of 75 variables tested and eliminated, including: marital status, income, age, major field of study and Kuwait University position (students vs faculty and staff).

BF knowledge transferred from mothers to daughters may be partly represented by nationalities (a proxy for culture) and may only become positively reinforced through action (ie, being breast fed as an infant). Family values need to be reinforced to preserve the traditional BF practices. ${ }^{38}$ Missing traditional family values and peer support for women might have a negative impact on the preservation of valuable BF practices among women, as seen in other societies in transition. ${ }^{39}$ In India, Pandey et a $\vec{l}^{39}$ showed that despite the educational progress of Indian women and their high level of awareness with regards to BF issues, an attitude to practice the same was found lacking.

This study had several limitations. First, the sample was collected from students and staff at one college at KU. Therefore, the generalisability of the findings is limited and may not include all women in KU. Second, the generalisability of the findings is further limited to college students and staff, as they may have higher knowledge levels and more positive attitudes toward BF than the general population. Larger studies are required to further understand how knowledge of and attitudes toward BF can be barriers to BF among all women in Kuwait.

\section{CONCLUSION}

This study examined women's own experience with being breast fed or exposed to $\mathrm{BF}$, along with knowledge of BF's positive health effects for infants and mothers, and attitudes toward BF to determine what factors influenced the choice to initiate and continue BF. Our study showed that even among highly educated women, their attitudes toward BF were influenced by prior exposure to BF through family interactions. This study is relevant and novel in that it adds new information about barriers to BF that may help explain the low prevalence in many countries, despite the known benefits. Furthermore, it shows that in some cultures, providing more knowledge on $\mathrm{BF}$ does not necessarily improve or change attitudes or decision toward BF. To overcome those BF barriers, more efforts are needed in Kuwait to encourage women of all walks of life to converse about BF benefits to the mother and baby and encourage BF. This can be achieved by providing prenatal classes to all expectant women with the involvement of their spouses and mothers. Hospitals and clinical practices should prioritise education and support for women to breast feed and provide adequate facilities and care routines to facilitate communication between family members. Interventions during pregnancy and after birth are necessary to support BF and provide guidance through individual or group sessions. Governmental health services need to emphasise and support the importance of regular training programme to all hospital staff involved in prenatal and antenatal clinics, and maternity wards as they can influence the early infant feeding practices among the new generation of mothers. In addition, the Health Ministry policy mandating that all government funded hospitals follow the 10 steps to successful $\mathrm{BF}$ and attain BFHI accreditation would promote successful BF among Kuwaiti women.

\section{Twitter Dalal Usamah Alkazemi @Dalal_Alkazemi}

Acknowledgements The authors acknowledge the participants of the study and would like to thank the students at the Department of Food Science and Nutrition who helped in data collection.

Contributors DUA conceived and designed the study. DUA coordinated data collection and entry and performed the statistical analysis. DUA and RJ wrote the manuscript. Both authors have critically reviewed and approved the final draft and are responsible for the content and similarity index of the manuscript.

Funding The authors have not declared a specific grant for this research from any funding agency in the public, commercial or not-for-profit sectors.

Competing interests None declared.

Patient consent for publication Signed informed consent was obtained from all participants who were advised that they could withdraw from the study for any reason.

Ethics approval Kuwait University Administration approved this protocol before study implementation, and approval for human subjects' research was obtained 
from the Department of Food Science and Nutrition Research Committee. No further approvals were required.

Provenance and peer review Not commissioned; externally peer reviewed.

Data availability statement Data are available upon reasonable request.

Open access This is an open access article distributed in accordance with the Creative Commons Attribution Non Commercial (CC BY-NC 4.0) license, which permits others to distribute, remix, adapt, build upon this work non-commercially, and license their derivative works on different terms, provided the original work is properly cited, appropriate credit is given, any changes made indicated, and the use is non-commercial. See: http://creativecommons.org/licenses/by-nc/4.0/.

ORCID iD

Dalal Usamah Alkazemi http://orcid.org/0000-0001-9349-2144

\section{REFERENCES}

1 Imdad A, Yakoob MY, Bhutta ZA. Effect of breastfeeding promotion interventions on breastfeeding rates, with special focus on developing countries. BMC Public Health 2011;11 Suppl 3:S24-32.

2 Bagci Bosi AT, Eriksen KG, Sobko T, et al. Breastfeeding practices and policies in who European region member states. Public Health Nutr 2016;19:753-64.

3 Rollins NC, Bhandari N, Hajeebhoy N, et al. Why invest, and what it will take to improve breastfeeding practices? The Lancet 2016;387:491-504.

4 World Health Organization. Global targets 2025. to improve maternal, infant and young child nutrition. Available: http://www.who.int/ nutrition/global-target-2025/en/ [Accessed Jun 2017].

5 Chowdhury R, Sinha B, Sankar MJ, et al. Breastfeeding and maternal health outcomes: a systematic review and meta-analysis. Acta Paediatr 2015;104:96-113.

6 Horta BL, Loret de Mola C, Victora CG. Long-term consequences of breastfeeding on cholesterol, obesity, systolic blood pressure and type 2 diabetes: a systematic review and meta-analysis. Acta Paediatr 2015;104:30-7.

7 AlSumaie M. Kuwait world breastfeeding trends initiative report. Kuwait breastfeeding promotion and BFHI implementation Committee in collaboration with international baby food action network (IBFAN) Asia. Ministry of health, Kuwait. Available: http:// www.worldbreastfeedingtrends.org/GenerateReports/report/WBTiKuwait-2015.pdf [Accessed Mar 2017].

8 Dashti M, Scott JA, Edwards CA, et al. Determinants of breastfeeding initiation among mothers in Kuwait. Int Breastfeed J 2010;5:7.

9 Dashti M, Scott JA, Edwards CA, et al. Predictors of breastfeeding duration among women in Kuwait: results of a prospective cohort study. Nutrients 2014;6:711-28.

10 Nassar MF, Abdel-Kader AM, Al-Refaee FA, et al. Breastfeeding practice in Kuwait: determinants of success and reasons for failure. East Mediterr Health J 2014;20:409-15.

11 Amir LH, Donath S. A systematic review of maternal obesity and breastfeeding intention, initiation and duration. BMC Pregnancy Childbirth 2007;7:9.

12 Mossman M, Heaman M, Dennis C-L, et al. The influence of adolescent mothers' breastfeeding confidence and attitudes on breastfeeding initiation and duration. J Hum Lact 2008;24:268-77.

13 Giles M, Connor S, McClenahan C, et al. Attitudes to breastfeeding among adolescents. J Hum Nutr Diet 2010;23:285-93.

14 Marrone S, Vogeltanz-Holm N, Holm J. Attitudes, knowledge, and intentions related to breastfeeding among university undergraduate women and men. J Hum Lact 2008;24:186-92.

15 Osman H, El Zein L, Wick L. Cultural beliefs that may discourage breastfeeding among Lebanese women: a qualitative analysis. Int Breastfeed J 2009;4:12

16 Ebrahim B, Al-Enezi H, Al-Turki M, et al. Knowledge, misconceptions, and future intentions towards breastfeeding among female university students in Kuwait. J Hum Lact 2011;27:358-66.
17 Dallak AM, Al-Rabeei NA, Aljahmi YA. Breastfeeding knowledge, attitude, and practices among mothers attending health centers in Sana'a City. ARC J Public Health Community Med 2016;1:9-17.

18 Ayed A. Knowledge, attitude and practice regarding exclusive breastfeeding among mothers attending primary health care centers in Abha City. Int J Med Sci Public Health 2014;3:1355-63.

19 Eldeek BS, Tayeb SO, Habiballah SB. Knowledge, attitudes and practice of mothers toward breastfeeding at well baby clinic, King Abdulaziz university hospital. J Am Sci 2012;8:157-62.

20 Amin TT, Abdulrahman AG, Al Muhaidib NS, et al. Breastfeeding attitudes and knowledge among future female physicians and teachers in Saudi Arabia. Health Sci J 2014;8:102-9.

21 Aldomi HA. Knowledge and attitudes towards breastfeeding among unmarried female graduates at the University of Jordan. Malays $J$ Nutr 2015;21:309-19.

22 Hamade H, Naja F, Keyrouz S, et al. Breastfeeding knowledge, attitude, perceived behavior, and intention among female undergraduate university students in the middle East: the case of Lebanon and Syria. Food Nutr Bull 2014;35:179-90.

23 Tarrant M, Dodgson JE. Knowledge, attitudes, exposure, and future intentions of Hong Kong university students toward infant feeding. Journal of Obstetric, Gynecologic \& Neonatal Nursing 2007;36:243-54.

24 Lou Z, Zeng G, Orme JG, et al. Breastfeeding knowledge, attitudes, and intention in a sample of undergraduate students in mainland China. J Hum Lact 2014;30:331-9.

25 De La Mora A, Russell DW. The lowa infant feeding attitude scale: analysis of reliability and validity. J App/ Soc Psychol 2006;29:262-80.

26 Tamim H, Ghandour LA, Shamsedine L, et al. Adaptation and validation of the Arabic version of the infant breastfeeding knowledge questionnaire among Lebanese women. J Hum Lact 2016;32:682-8.

27 Collaborative Group on Hormonal Factors in Breast Cancer. Breast cancer and breastfeeding: collaborative reanalysis of individual data from 47 epidemiological studies in 30 countries, including 50302 women with breast cancer and 96973 women without the disease. The Lancet 2002;360:187-95.

28 Khadduri R, Marsh DR, Rasmussen B, et al. Household knowledge and practices of newborn and maternal health in Haripur district, Pakistan. J Perinatol 2008;28:182-7.

29 al-Ayed IH, Qureshi MI. Breastfeeding practices in urban Riyadh. $J$ Trop Pediatr 1998:44:113-7.

30 Sherriff N, Hall V, Panton C. Engaging and supporting fathers to promote breast feeding: a concept analysis. Midwifery 2014;30:667-77.

31 Ogbeide DO, Siddiqui S, AI Khalifa IM, et al. Breast feeding in a Saudi Arabian community. profile of parents and influencing factors. Saudi Med J 2004;25:580-4.

32 . Implementation guidance: protecting, promoting and supporting breastfeeding in facilities providing maternity and newborn services - the revised Baby-friendly Hospital initiative. Licence: CC BY-NC-SA 3.0 IGO. Geneva World Health Organization; 2018.

33 Gatrad AR, Sheikh A. Muslim birth customs. Arch Dis Child Fetal Neonatal Ed 2001;84:6F-8.

34 Pérez-Escamilla R. Evidence based breast-feeding promotion: the Baby-Friendly Hospital initiative. J Nutr 2007;137:484-7.

35 Desmond D, Meaney S. A qualitative study investigating the barriers to returning to work for breastfeeding mothers in Ireland. Int Breastfeed J 2016;11.

36 Nabulsi M. Why are breastfeeding rates low in Lebanon? A qualitative study. BMC Pediatr 2011:11:1-6.

37 Turcksin R, Bel S, Galjaard S, et al. Maternal obesity and breastfeeding intention, initiation, intensity and duration: a systematic review. Matern Child Nutr 2014;10:166-83.

38 Rubin L, Nir-Inbar S, Rishpon S. Breastfeeding patterns among Ethiopian immigrant mothers, Israel, 2005-2006. Isr Med Assoc $J$ 2010;12:657-61.

39 Pandey D, Sardana P, Saxena A, et al. Awareness and attitude towards breastfeeding among two generations of Indian women: a comparative study. PLoS One 2015;10:e0126575. 